\title{
Arachnoid cysts and adult onset epilepsy
}

\author{
Trisha Mackle MD MSc, Daryl Wile MD MSc
}

Cite as: CMAJ 20172017 February 21;189:E280. doi: 10.1503/cmaj.160423

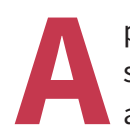
previously healthy 72-year-old woman presented to the emergency department after awakening from sleep with several minutes of impaired responsiveness, lip smacking and complex motor movements of her limbs. Subsequently, she had multiple brief episodes of altered level of consciousness and leftward eye deviation. In retrospect, she recalled occasional transient spells of colourful visual phenomena in recent years, but the rest of her history was unremarkable. Her vital signs were normal. The patient had a normal Glasgow Coma Scale score of 15, and neurologic examination showed an upgoing plantar response on the left side but was otherwise normal.

Computed tomography (CT) of the head showed a large arachnoid cyst overlying the right hemisphere, with radiographic features suggesting a chronic lesion (i.e., thinning of the overlying bone and lack of substantial midline shift) (Figure 1). Magnetic resonance imaging (MRI) features supported the diagnosis of an arachnoid cyst (Appendix 1, available at www.cmaj.ca/lookup/suppl/doi:10.1503/cmaj.160423/-/DC1).

Although this patient's clinical history and imaging abnormality immediately raised suspicion of seizure onset in the right hemisphere, electroencephalography showed focal slowing of the structurally normal left hemisphere. This suggested a complex cause that may, for instance, involve bilateral abnormalities predisposing this patient to seizures. Neurosurgery was consulted for an opinion and recommended conservative management. The patient was treated with lamotrigine, which was well tolerated, and had no recurrent spells at follow-up after 6 months.

Arachnoid cysts are collections of cerebrospinal fluid contained between layers of arachnoid membrane that result from congenital developmental defects or trauma. They are found in all age groups and account for about $1 \%$ of intracranial mass lesions. ${ }^{1}$ Only a few patients will be symptomatic; symptoms vary with cyst location and can include headache, seizure, ataxia, dizziness, visual changes and nausea. ${ }^{2}$

Management of these cases is controversial because arachnoid cysts are often incidental findings that correlate poorly with specific seizure type and electroencephalogram focus. ${ }^{3}$ It is prudent to consider alternative causes of seizure.

Symptomatic patients may be candidates for surgery; operative management may improve symptoms such as headache or dizzi- ness in some patients. ${ }^{4}$ However, most lesions are considered incidental and can be treated conservatively. ${ }^{1,2}$

\section{References}

1. Pradilla G, Jallo G. Arachnoid cysts: case series and review of the literature. Neurosurg Focus 2007;22:E7.

2. Al-Holou WN, Terman S, Kilburg C, et al. Prevalence and natural history of arachnoid cysts in adults. J Neurosurg 2013;118:222-31.

3. Yalçin AD, Oncel C, Kaymaz A, et al. Evidence against association between arachnoid cysts and epilepsy. Epilepsy Res 2002;49:255-60.

4. Mørkve SH, Helland CA, Amus J, et al. Surgical decompression of arachnoid cysts leads to improved quality of life: a prospective study. Neurosurgery 2016;78:613.

\section{Competing interests: None declared.}

This article has been peer reviewed.

The authors have obtained patient consent.

Affiliations: Department of Emergency Medicine (Mackle); Department of Medicine (Wile), Division of Neurology, Kelowna General Hospital, Kelowna, BC

Correspondence to: Trisha Mackle, mackle@alumni.ubc.ca 